\title{
POPULATION STUDY ARTICLE Growth and changes in the pediatric medical subspecialty workforce pipeline
}

\author{
Michelle L. Macy ${ }^{1,2,7}$, Laurel K. Leslie ${ }^{3,4}$, Adam Turner ${ }^{3}$ and Gary L. Freed ${ }^{1,5,6}$
}

BACKGROUND: To inform discussions of pediatric subspecialty workforce adequacy and characterize its pipeline, we examined trends in first-year fellows in the 14 American Board of Pediatrics (ABP)-certified pediatric medical subspecialties, $2001-2018$. METHODS: Data were obtained from the ABP Certification Management System. We determined, within each subspecialty, the annual number of first-year fellows. We assessed for changes in the population using variables available throughout the study period (gender, medical school location, program region, and program size). We fit linear trendlines and calculated $x^{2}$ statistics. RESULTS: The number of first-year pediatric medical subspecialty fellows increased from 751 in 2001 to 1445 in 2018. Fields with the growth of 3 or more fellows per year were Cardiology, Critical Care, Emergency Medicine, Gastroenterology, Neonatology, and Hematology Oncology ( $P$ value $<0.05$ for all). The number of fellows entering Adolescent Medicine, Child Abuse, Infectious Disease, and Nephrology increased at a rate of 0.5 fellows or fewer per year. Female American Medical Graduates represented the largest and growing proportions of several subspecialties. Distribution of programs by region and size were relatively consistent over time, but varied across subspecialties.

CONCLUSIONS: The number of pediatricians entering medical subspecialty fellowship training is uneven and patterns of growth differ between subspecialties.

Pediatric Research (2021) 89:1297-1303; https://doi.org/10.1038/s41390-020-01311-7

\section{IMPACT:}

- The number of individuals entering fellowship training has increased between 2001 and 2018.

- Growth in the number of first-year fellows is uneven.

- Fields with the greatest growth: Critical Care, Emergency Medicine, and Neonatology.

- Fields with limited growth: Adolescent Medicine, Child Abuse, Infectious Disease, and Nephrology.

- Concerns about the pediatric medical subspecialty workforce are not explained by the number of individuals entering the fellowship.

\section{INTRODUCTION}

The adequacy of the pediatric subspecialty workforce has been a concern for decades, ${ }^{1-4}$ despite increasing numbers of individuals entering pediatric residency programs in the United States. ${ }^{5}$ Some pediatric fellowship programs experience difficulty filling their available positions, 6,7 and without sufficient providers to meet the specialty care needs of children, there is a lack of timely access. ${ }^{8-10}$ A recent Children's Hospital Association (CHA) survey of pediatric hospitals found waiting times for many subspecialties to be several weeks. ${ }^{11}$ In addition, some families face a substantial travel burden when obtaining care because of the uneven geographic distribution of pediatric subspecialists, particularly for smaller fields like Rheumatology. ${ }^{12}$ Other papers and editorials have presented the state of the pediatric subspecialty in a positive light, ${ }^{3}$ citing increases in the overall number of pediatricians entering subspecialty training programs ${ }^{1}$ and growth in some subspecialties. $^{13,14}$
The linkage between the pipeline of pediatric subspecialists and actual shortages of providers with the clinical capacity to care for children with subspecialty needs throughout the United States is complex and difficult to establish. A full picture requires an understanding of the pipeline of individuals entering into the subspecialty workforce and attrition due to part-time status or retirement, ${ }^{15,16}$ which have been amplified by shifts in the proportions of women and men in the workforce. ${ }^{17}$ The clinical capacity of pediatric subspecialists is diminished by professional commitments outside direct patient care (e.g., time spent in research, ${ }^{18}$ administration, and teaching) and mitigated through integrating other health professionals ${ }^{19-21}$ into practice. Changes in the epidemiology of childhood diseases and conditions ${ }^{22}$ influence the demand for pediatric subspecialty care. In addition to the number of available providers, access to pediatric subspecialty care is impacted by the geographic dispersion of subspecialists $^{9}$ and care models that incorporate telehealth. ${ }^{23-25}$

\footnotetext{
${ }^{1}$ Child Health Evaluation and Research (CHEAR) Center, Ann Arbor, MI, USA; ${ }^{2}$ Department of Emergency Medicine, University of Michigan, Ann Arbor, MI, USA; ${ }^{3}$ American Board of

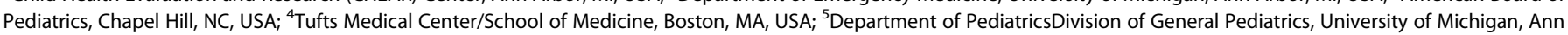
Arbor, MI, USA and ${ }^{6}$ Department of Health Management and Policy, University of Michigan, Ann Arbor, MI, USA

Correspondence: Michelle L. Macy (mmacy@luriechildrens.org)

${ }^{7}$ Present address: Department of Pediatrics, Ann \& Robert H. Lurie Children's Hospital of Chicago and Feinberg School of Medicine Northwestern University, Chicago, IL, USA
}

Received: 19 August 2020 Revised: 28 October 2020 Accepted: 10 November 2020

Published online: 16 December 2020 
Table 1. Change in the first-year fellows within pediatric medical subspecialties certified by the American Board of Pediatrics, 2001-2018.

\begin{tabular}{|c|c|c|c|c|c|c|c|c|c|c|c|c|}
\hline \multirow[t]{2}{*}{ Field (year of first board examination) } & \multicolumn{3}{|c|}{$\begin{array}{l}\text { Number of first-year } \\
\text { fellows }\end{array}$} & \multicolumn{3}{|c|}{ Trends 2001-2008 } & \multicolumn{3}{|c|}{ Trends 2009-2018 } & \multicolumn{3}{|c|}{ Trends 2001-2018 } \\
\hline & 2001 & 2009 & 2018 & Slope & $R^{2}$ & $P$ value & Slope & $R^{2}$ & $P$ value & Slope & $R^{2}$ & $P$ value \\
\hline Adolescent Medicine (1994) & 27 & 23 & 31 & -0.21 & 0.03 & 0.68 & 0.84 & 0.28 & 0.12 & 0.51 & 0.34 & 0.01 \\
\hline Cardiology (1961) & 68 & 127 & 154 & 6.14 & 0.75 & 0.006 & 2.51 & 0.86 & $<0.001$ & 4.35 & 0.90 & $<0.001$ \\
\hline Child Abuse (2009) ${ }^{a}$ & $\mathrm{~N} / \mathrm{A}$ & 9 & 18 & $\mathrm{~N} / \mathrm{A}$ & $\mathrm{N} / \mathrm{A}$ & N/A & 0.69 & 0.36 & 0.069 & 0.46 & 0.27 & 0.08 \\
\hline Critical Care (1987) & 92 & 148 & 193 & 5.87 & 0.73 & 0.007 & 6.09 & 0.94 & $<0.001$ & 6.06 & 0.96 & $<0.001$ \\
\hline Developmental Behavioral (2002) & 17 & 26 & 42 & 0.98 & 0.33 & 0.13 & 1.19 & 0.45 & 0.04 & 1.25 & 0.77 & $<0.001$ \\
\hline Emergency Medicine (1992) & 80 & 124 & 189 & 5.85 & 0.83 & 0.002 & 7.15 & 0.94 & $<0.001$ & 6.94 & 0.97 & $<0.001$ \\
\hline Endocrinology (1978) & 50 & 75 & 82 & 3.81 & 0.71 & 0.009 & -0.22 & 0.02 & 0.70 & 1.44 & 0.52 & 0.001 \\
\hline Gastroenterology (1990) & 45 & 84 & 113 & 4.81 & 0.97 & $<0.001$ & 2.72 & 0.92 & $<0.001$ & 3.49 & 0.97 & $<0.001$ \\
\hline Hematology Oncology (1974) & 87 & 143 & 161 & 6.21 & 0.89 & $<0.001$ & 2.35 & 0.57 & 0.01 & 4.63 & 0.90 & $<0.001$ \\
\hline Infectious Disease (1994) & 48 & 59 & 60 & 1.31 & 0.45 & 0.07 & -0.16 & 0.01 & 0.76 & 0.39 & 0.19 & 0.07 \\
\hline Neonatology (1975) & 166 & 222 & 268 & 8.08 & 0.83 & 0.002 & 5.40 & 0.88 & $<0.001$ & 5.72 & 0.93 & $<0.001$ \\
\hline Nephrology (1974) & 22 & 46 & 46 & 2.08 & 0.53 & 0.04 & -0.75 & 0.20 & 0.20 & 0.54 & 0.19 & 0.07 \\
\hline Pulmonary (1986) & 36 & 50 & 59 & 1.94 & 0.49 & 0.05 & 0.42 & 0.13 & 0.30 & 1.38 & 0.72 & $<0.001$ \\
\hline Rheumatology (1992) & 14 & 27 & 29 & 2.46 & 0.77 & 0.004 & 0.90 & 0.32 & 0.09 & 0.97 & 0.59 & $<0.001$ \\
\hline
\end{tabular}

${ }^{a} \mathrm{~N} / \mathrm{A}=$ not available as 2007 is the first year of data on Child Abuse fellows are available and 2009 was the first year of board certification

This paper examines one aspect of the supply side of the pediatric subspecialty workforce, the entry of individuals into the first year of fellowship training. We evaluated data from the American Board of Pediatrics (ABP) across multiple years to characterize and quantify recent trends in the number of first-year fellows entering the 14 ABP-certified pediatric medical subspecialties.

\section{METHODS}

Data were obtained from the ABP Certification Management System, used to generate yearly snapshots of the pediatric

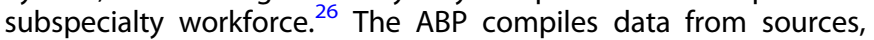
including trainee-level data provided by directors of pediatric subspecialty fellowship training programs accredited by the Accreditation Council for Graduate Medical Education and the Royal College of Physician and Surgeons in Canada. We focused our analyses on US program data available for the 14 ABP-certified subspecialties in 2018: Adolescent Medicine, Cardiology, Child Abuse, Critical Care, Developmental Behavioral, Emergency Medicine, Endocrinology, Gastroenterology, Hematology Oncology, Infectious Diseases, Neonatology, Nephrology, Pulmonology, and Rheumatology. The first board examination for Pediatric Hospital Medicine was offered in 2019 and therefore this field is not represented in the data. National Resident Matching Program data were used to determine program size in $2018 .^{27}$

We determined the number of first-year fellows in each subspecialty per year from 2001 to 2018 and described trends in the number of first-year fellows over time. We describe the composition of first-year pediatric subspecialty fellows using two demographic and two program characteristics available from the $A B P$ over the entire study period and known to influence career choices: $^{16,28,29}$ gender and medical school location [America Medical Graduate (AMG) or International Medical Graduate (IMG)]. During the study timeframe, the ABP collected data from trainees about their gender, not biological sex, using the binary response options male or female. The region was categorized as Northeast, Midwest, South, and West. Program size was categorized as 1-3, 4-6, 7-9, and 10 or more fellows. Program size has been shown to impact fellow's perceptions regarding the financial security of programs. ${ }^{30}$ For context, we present the number and proportion of female/male and AMG/IMG third-year residents in 2008 and 2017, ${ }^{5}$ as recent graduates from residency would represent the bulk of the pipeline into fellowship training. We also present information about the number of programs for each subspecialty. ${ }^{5}$ Program fill rates in 2018 were calculated using ABP data from all fellows in accredited programs as some programs allow fellows to enter training outside the match process. These data were used preferentially over the National Resident Matching Program "The Match" data as the ABP keeps a record of all fellows in accredited programs, not just fellows entering The Match process. ${ }^{27}$

We graphed the data, fit linear trendlines, and calculated $P$-fortrends for each subspecialty and the demographic characteristics of first-year fellows using Tableau 2019.2.3 (Seattle, WA) and SAS 7.15 (Cary, NC). We calculated $\beta$, or slope, representing the number of additional fellows year after year and $R^{2}$ values for the trendlines overall for 2001-2018. We also calculated $\beta$ and $R^{2}$ values for the trendlines for 2001-2008 and 2009-2018 to determine if the inflow of subspecialty fellows has changed in the most recent 10 years of data compared with the earlier time period. We conducted $x^{2}$ analyses to compare demographic and program characteristics at the start, middle, and end of the study period. The Cramer's post test was used to determine strengths of association given frequency tables that are larger than $2 \times 2$. $^{31}$ Lastly, we calculated the number and proportion of fellows within each subspecialty relative to program region and size in 2018. This use of the ABP workforce data does not constitute human subjects research per the University of Michigan Institutional Review Board.

\section{RESULTS}

Number of first-year fellows entering pediatric subspecialties over time

In 2001, there were 751 first-year fellows across the 14 ABPcertified subspecialties included in this study. By 2018, that number had nearly doubled to 1445 . For all fields, there was an increase in the absolute number of first-year fellows comparing 2018 with 2001. In general, growth was greater in fields with 50 or more first-year fellows in 2001 (Neonatology, Critical Care Medicine, Emergency Medicine, Hematology Oncology, Cardiology, Gastroenterology, Endocrinology) and more modest in fields with fewer than 50 first-year fellows in 2001 (Infectious Disease, Pulmonology, Nephrology, Developmental Behavioral, Adolescent 
Table 2. Demographic characteristics of first-year fellows and program characteristics over the study period.

\begin{tabular}{|c|c|c|c|c|c|c|c|}
\hline & \multicolumn{2}{|l|}{2001} & \multicolumn{2}{|l|}{2009} & \multicolumn{2}{|l|}{2018} & $P$ value* (Cramer's $V$ \\
\hline Gender & & & & & & & $<0.0001(0.14)$ \\
\hline Male & 49.9 & 375 & 37.1 & 434 & 32.3 & 467 & \\
\hline Female & 50.1 & 377 & 62.9 & 731 & 67.7 & 978 & \\
\hline IMG & 31.0 & 233 & 29.3 & 341 & 27.7 & 400 & \\
\hline Subspecialty & & & & & & & 0.24 \\
\hline Adolescent Medicine & 3.6 & 27 & 2.0 & 23 & 2.1 & 31 & \\
\hline Cardiology & 9.0 & 68 & 10.9 & 127 & 10.7 & 154 & \\
\hline Child Abuse $^{a}$ & $\mathrm{n} / \mathrm{a}$ & $\mathrm{n} / \mathrm{a}$ & 0.8 & 9 & 1.2 & 18 & \\
\hline Endocrinology & 6.7 & 50 & 6.4 & 75 & 5.7 & 82 & \\
\hline Gastroenterology & 6.0 & 45 & 7.2 & 84 & 7.8 & 113 & \\
\hline Hematology Oncology & 11.6 & 87 & 12.3 & 143 & 11.1 & 161 & \\
\hline Infectious Disease & 6.4 & 48 & 5.1 & 59 & 4.2 & 60 & \\
\hline Neonatology & 22.1 & 166 & 19.1 & 222 & 18.5 & 268 & \\
\hline Nephrology & 2.9 & 22 & 4.0 & 46 & 3.2 & 46 & \\
\hline Pulmonology & 4.8 & 36 & 4.3 & 50 & 4.1 & 59 & \\
\hline Rheumatology & 1.9 & 14 & 2.3 & 27 & 2.0 & 29 & \\
\hline \multicolumn{8}{|l|}{ Program characteristics } \\
\hline Region & & & & & & & 0.07 \\
\hline 7-9 Fellows & 16.5 & 124 & 23.7 & 276 & 21.6 & 312 & \\
\hline$\geq 10$ Fellows & 14.1 & 106 & 21.0 & 244 & 28.9 & 418 & \\
\hline
\end{tabular}

Medicine, Rheumatology, Child Abuse). Neonatology had the most first-year fellows throughout the study period and grew from 166 in 2001 to 268 in 2018. Child abuse, which became an ABPcertified subspecialty in 2009, had the fewest first-year fellows each year, 9 in 2009 and 18 in 2018.

Trendline statistics for 2001-2008, 2009-2018, and the entire period for each subspecialty are presented in Table 1. The greatest increase in first-year fellows was observed for Emergency Medicine with nearly 7 additional fellows per year. Critical Care Medicine, Hematology Oncology, Cardiology, and Gastroenterology showed an increase of 3 fellows or more per year. Four of the subspecialties, Adolescent Medicine, Child Abuse, Nephrology, and Infectious Diseases, had an increase of 0.5 fellows or fewer per year. Infectious Disease had only one more first-year fellow in 2018 than in 2001. While many of the remaining subspecialties had statistically significant increases in the number of first-year fellows, the trends were marginally positive.

Critical Care Medicine, Developmental Behavioral, Emergency Medicine, and Gastroenterology had more growth in the most recent 10 years than the earlier time period, whereas Cardiology, Hematology, Neonatology, Pulmonary, and Rheumatology had smaller increases in the most recent 10 years than prior years. The slope of the trendlines went from negative to positive for Adolescent Medicine and from positive to negative for Endocrinology, Infectious Disease, and Nephrology. Child Abuse had insufficient data for this analysis.

First-year fellows: demographic and program characteristics Table 2 compares the demographic characteristics of first-year fellows in 2001, 2009, and 2018. Overall, there was an increase in the number of women and men entering fellowship across the three time points analyzed for this study (2001, 2009, and 2018), but the proportion of first-year fellows who were women increased from $50.1 \%$ in 2001 to $67.7 \%$ in 2018, while the proportion of first-year fellows who were men decreased from 49.9\% in 2001 to $32.3 \%$ in $2018(P<0.001$ [Cramer's $V=0.14$ ]). In only two fields, Cardiology and Critical Care Medicine, at any time did more men than women enter fellowship. To place these 
Table 3. Distribution of first-year fellows by the size of fellowship program by a subspecialty in 2018 .

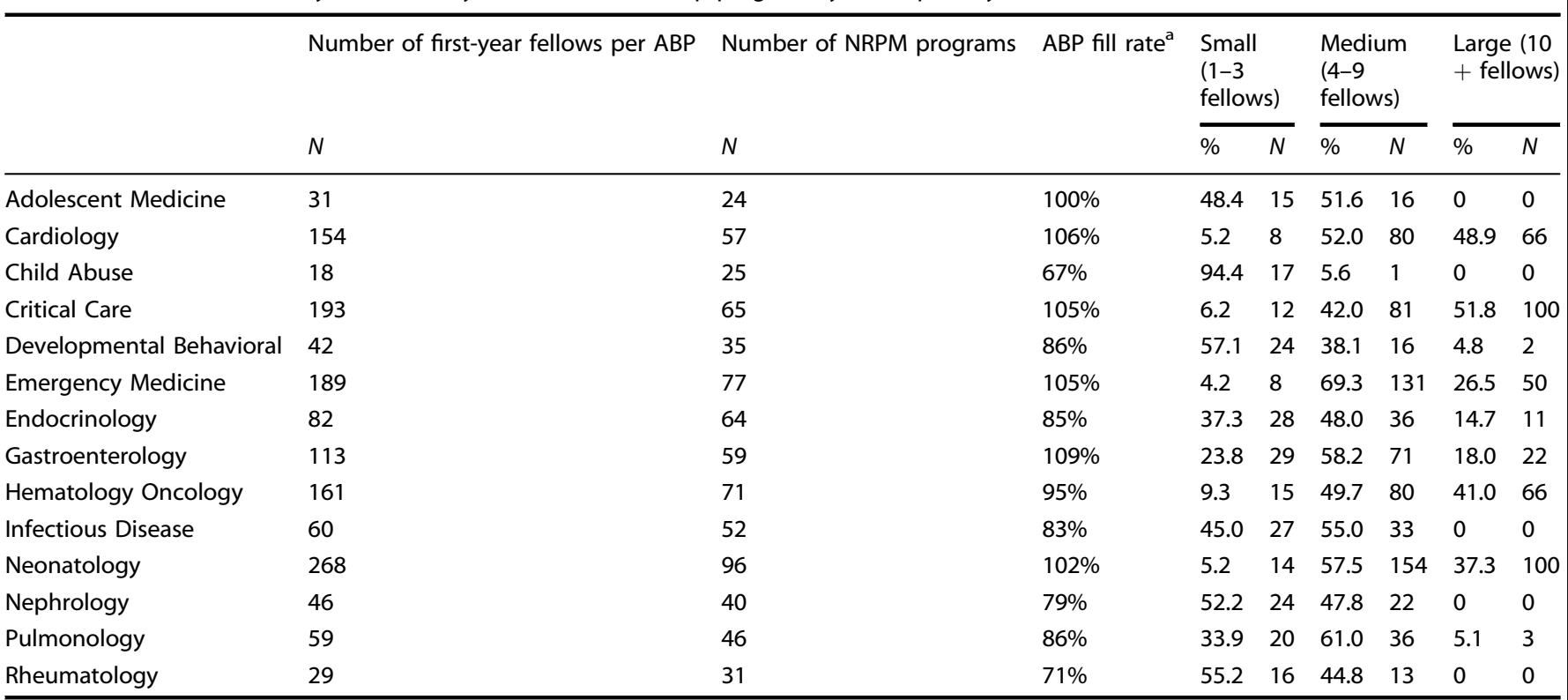

${ }^{\mathrm{a} A B P}$ fill rates were calculated using data on the total fellows reported to the American Board of Pediatrics internal training data system and the number of open positions in the National Residency Match Program. ABP fill rates can be $>100 \%$ because some fellowship programs allow for entry outside of the Match.

findings into context, there were $870(28.6 \%)$ male and 2169 (71.4\%) female third-year residents in 2008 and 956 (28.6\%) male and 2382 (71.4\%) female third-year residents in 2017. If we assume that most pediatricians entering fellowship do so immediately following their graduation from residency, $\sim 50 \%$ of male residents and $34 \%$ of female residents entered a fellowship in 2009 and $49 \%$ of male residents and $41 \%$ of female residents entered a fellowship in 2018 ( $P<0.0001$ for females).

Likewise, there was an increase in the number of AMGs and IMGs entering fellowship across the three time points analyzed for this study (2001, 2009, and 2018). Yet, there was minimal change in the overall proportions of first-year fellows who were AMGs over this period, $69.0 \%$ in 2001 and $72.3 \%$ in 2018; the proportions of first-year fellows who were IMGs ranged from 31.0\% in 2001 to $27.7 \%$ in $2018(P=0.26)$. AMGs predominated in all fields but Nephrology, which had more IMGs in several years. For context, there were $671(22.1 \%)$ IMGs and 2368 (77.9\%) AMG third-year residents in 2008 and 571 (17.1\%) IMG and 2767 (82.9\%) AMG third-year residents in 2017. Assuming that most of the third-year residents entered fellowship the following year, $48.3 \%$ of IMGs and $35.2 \%$ of AMGs entered a fellowship in 2008 and $70.1 \%$ of IMGs and $37.8 \%$ of AMGs entered a fellowship in $2018(P<0.0001$ for IMGs).

Considering these demographic characteristics together (data not shown), female AMGs drove growth in the fields of Emergency Medicine, Neonatology, Critical Care, Hematology Oncology, Cardiology, Gastroenterology, Developmental Behavioral, and Child Abuse. There was a decline in female AMGs in the fields of Endocrinology and Infectious Diseases over the study period.

The regional distribution of first-year fellows changed marginally between 2001 and $2018(P=0.01$ [Cramer's $V=0.07$ ]). (Table 2). The geographic distribution of first-year fellows in 2018 followed a similar pattern across many fields, with most fellows training in the South (32.2\%), fewest fellows training in the West $(17.4 \%)$. The proportions of fellows training in the Northeast and Midwest were $26.2 \%$ and $24.2 \%$, respectively. There were distinct geographic patterns for some fields in 2018. Adolescent Medicine had higher proportions of fellows training in the Northeast (32.2\%) and West (22.6\%) than the South (25.8) and
Midwest (19.3)). Developmental Behavioral had higher proportions of fellows training in the Northeast (40.5\%) and West (23.8\%) than in the Midwest (21.4\%) and South (14.3\%). Endocrinology had higher proportions of training in the Northeast (35.4\%) than in the South (28.0\%), Midwest (20.7\%), and West (15.9\%).

Compared with 2001, more first-year fellows entered large programs (10 fellows or more) in 2009 and 2018, $(P=0.0001$ [Cramer's $V=0.13$ ]) (Table 2). There was a concurrent decrease in the proportion of first-year fellows in small programs (1-3 fellows). In 2001, 33.1\% of first-year fellows entered small programs and $14.1 \%$ entered large programs. By $2018,17.3 \%$ of first-year fellows entered small programs and $28.9 \%$ entered large programs $(P<$ 0.001 [Cramer's $V=0.13$ ]). In 2018, the number of fellowship programs ranged from 24 (Adolescent Medicine) to 96 (Neonatology) and the fill rates including all trainees reporting to the ABP were lowest for Child Abuse (66.7\%) and Rheumatology (70.7\%) and highest for Gastroenterology (108.7\%) and Cardiology (106.2\%) (Table 3). The distribution of fellows in 2018 across program size varied by subspecialty (Table 3 ). The five largest subspecialties in 2018 (Emergency Medicine, Neonatology, Critical Care, Hematology Oncology, and Cardiology) had $<10 \%$ of fellows entering small programs, $40-70 \%$ of fellows entering mediumsized programs, and $26-52 \%$ of fellows entering large programs. Subspecialties with 50-125 first-year fellows in 2018 (Gastroenterology, Endocrinology, Pulmonary, and Infectious Disease) had 24$45 \%$ of fellows entering small programs, 48-61\% entering medium-sized programs, and $<18 \%$ entering large programs. Five subspecialties (Rheumatology, Nephrology, Adolescent Medicine, Child Abuse, and Infectious Disease) had no large programs in 2018.

\section{DISCUSSION}

The most important finding in this study was the overall steep increase in the total number of pediatricians entering subspecialty fellowship training over the past 18 years. However, the growth across subspecialties has been uneven and for many subspecialties, the rate of growth has changed in the most recent 10 years compared with the earlier timeframe. While policies 
implemented by the ABP determine whether to offer certification for a pediatric subspecialty, the ABP does not determine the numbers, size, or locations of fellowship programs. These decisions are driven by multiple factors including graduate medical education policies and resultant funding opportunities as well as local factors.

Our results illustrate the importance of examining disaggregated data in pediatric subspecialty workforce analyses to better understand the contributions of each subspecialty to the overall picture and the context within which we consider the supply of pediatric subspecialists in the United States. ${ }^{3}$ Subspecialties with fewer than 50 fellows each year, including Adolescent Medicine, Child Abuse, Nephrology, and Developmental Behavioral, have remained small. Subspecialties with $>75$ fellows each year, including Neonatology, Critical Care Medicine, Emergency Medicine, and Hematology Oncology, have seen marked increases in individuals entering fellowship training since 2008. Individuals interested in monitoring workforce trends can do so on the ABP's Interactive Workforce Data website (www.abp.org/content/ workforce). ${ }^{26}$

The rate of entry into specific subspecialty fields has changed over time. The differential selection of some subspecialty fields over others may contribute to perceptions of workforce shortages ${ }^{1-3,22,32}$ and selection of a field of specialization is, in part, shaped by training. Prior research has demonstrated that pediatric residents often enter the intern year with an interest in pediatric subspecialty careers and choice of subspecialty is shaped during residency training. ${ }^{33}$ Specific factors that were important to the choice of subspecialty field were explored in the 2019 American Academy of Pediatrics (AAP) Annual Survey of Graduating Residents. ${ }^{34}$ Among 188 individuals who planned to pursue fellowship training, the most commonly selected factors were future job opportunities, interest in the specific disease/organ system, exposure to the subspecialty, mentors during residency, and teaching opportunities. The least commonly selected factors were the level of education debt and the ability to stay at the same institution. These factors may be considered in efforts to encourage entry into specific pediatric subspecialty fields.

Our results highlight changes in the demographic characteristics of first-year pediatric subspecialty fellows based on the two variables that have been tracked over time by the ABP, including trainee-reported gender and graduation from an American or international medical school. The proportion of women entering first-year fellows has been increasing, driven by greater growth in the number of women than men entering fellowship. Fewer fellowship programs had first-year classes that were predominantly men in 2018 compared with a 2005 publication that showed male predominance in cardiology, critical care, gastroenterology, neonatology, nephrology, and pulmonary. ${ }^{35}$ Our results related to the proportion of men and women entering fellowship training are mirrored in results from the 2019 AAP Annual Survey, which found $41 \%$ of men and $37 \%$ of women reported starting a pediatric fellowship after residency training. ${ }^{27}$ These proportions vary substantially from those of first-year pediatric residents, with $71 \%$ women and $29 \%$ men entering residency in 2018. ${ }^{33}$ Although factors important to men and women in their selection of subspecialty were noted to be similar in the AAP survey, ${ }^{34}$ one can hypothesize possible reasons why women still remain a reduced proportion of first-year fellows compared with third-year pediatric residents, but they are entering some subspecialty fields in greater numbers and proportions in more recent years. Women may be seeking higher-paying positions in fields like Cardiology or more flexible hours in fields such as Emergency Medicine. They may be pursuing careers that integrate clinical care with other professional activities, such as research, education, and administration or responding to calls for equity in the healthcare workforce and within pediatrics. ${ }^{36}$
While the overall pattern for AMG and IMG pediatricians was more consistent over the study period, there are microtrends that may be contributing to changes in the workforce in certain fields. IMGs contributed more to the growth in first-year fellows in Endocrinology, Pulmonology, and Infectious Disease and to a lesser extent in Development Behavioral than AMGs. Historically, IMGs have filled a substantial number of fellowship positions, although this has fluctuated markedly over time. ${ }^{1,28,37} \mathrm{New}$ restrictions in US immigration policy in 2018 and the impact of the COVID-19 pandemic may influence both the number of pediatricians from outside the United States who enter fellowship and the number who go on to practice in the United States after completion of training may decrease. ${ }^{38}$ Access to pediatric subspecialists, particularly in medically underserved areas, may be hindered if there are fewer individuals with $\mathrm{J}-1$ visa service requirements. ${ }^{39,40}$

There are fields including Child Abuse, Developmental Behavioral, Infectious Disease, Nephrology, Pulmonology, and Rheumatology with smaller numbers of first-year fellows, lower fill rates, and higher proportions of first-year fellows in small programs. The future of fellowship training programs such as these may be challenged by the financial strain experienced by children's hospitals in the setting of lower patient volumes during the COVID-19 pandemic. ${ }^{41,42}$ These financial strains may have an impact on the viability of subspecialty fellowship programs that are supported on operational funds. Small programs faced financial insecurity ${ }^{30}$ even prior to the economic shock of the COVID-19.

Our results show that fellowship programs are not evenly distributed throughout the country. The regional distribution of training programs, and, in turn, the location of faculty positions in academic medical centers, may contribute to where subspecialists eventually practice in addition to the availability of positions. Examining the relationship between training location for an individual to their practice location as a board-certified subspecialist is a potential area for future study. The geographic maldistribution of pediatric subspecialists has been documented $^{4,43}$ and the board-certified pediatric subspecialists per 100,000 children throughout the United States can be visualized on the ABP Workforce Dashboard. ${ }^{26}$ The increase in the number of pediatric subspecialists nationally has resulted in an increase in the number of subspecialists per 100,000 children in hospital referral regions and a reduction in the mean distance from the US child population to the nearest provider. ${ }^{12}$ In a 2006 publication, mean distance from the US child population to the nearest provider ranged from 15 miles for Neonatology (the largest pediatric subspecialty) to 60 miles for Rheumatology (one of the smallest pediatric subspecialties). ${ }^{44}$ Even with decreases in the average distance, a family would need to travel for subspecialty care ranging from 12 miles for Neonatology to 43 miles for Rheumatology, millions of families still face travel burdens and longer wait times for appointments.

Health plan design can further limit or increase access to subspecialists. In a 2014 analysis, the availability of pediatric subspecialists in Affordable Care Act Marketplace Plan insurance networks was most limited for Infectious Disease, Nephrology, and Neonatology. ${ }^{45}$ The rapid expansion of telehealth services in response to the COVID-19 pandemic ${ }^{46}$ creates new opportunities to overcome geographic barriers to accessing pediatric subspecialty care. ${ }^{47}$ Health plan design and telehealth policies should account for the pediatric subspecialty needs of children throughout the United States.

Multiple other factors likely contribute to perceived shortages in the subspecialty workforce ${ }^{2,11,48}$ and the hypotheses that follow warrant further study. As the medically complex child population continues to grow, ${ }^{22}$ so does the need for subspecialty care. New areas of sub-subspecialization, within narrow niches and requiring a fourth-year of training have emerged in some fields such as 
Cardiology ${ }^{49}$ and Hematology Oncology. ${ }^{50}$ This subsubspecialization may decrease the subspecialists who evaluate children for a broad range of conditions in a given subspecialty despite the growth observed in these fields. Although there has been limited research examining outcomes for children with medical conditions cared for by general or subspecialty pediatricians and by adult or pediatric subspecialists, differences in knowledge, patient characteristics, and processes of care have been described. ${ }^{51-53}$ New initiatives to enrich the training of pediatric residents in fields with a paucity of pediatric subspecialists could help decrease reliance on subspecialists for some conditions and concerns. ${ }^{54}$

The allocation of time to direct patient care may reduce available clinic appointments within some subspecialties. ${ }^{18,29}$ In the fields of Endocrinology, Hematology Oncology, Infectious Disease, Nephrology, Pulmonology, and Rheumatology, as much as $15 \%$ of the workforce devotes at least $25 \%$ of their professional time to research. ${ }^{18}$ The effective workforce is further diminished by individuals who work part-time; $\sim 10 \%$ of pediatric subspecialists work part-time ${ }^{4}$ with variation across subspecialties. ${ }^{16}$ The rate of attrition of individuals from fellowship training and clinical practice due to burnout may be exacerbated by discrepancies in work-life balance between women and men. ${ }^{17}$ Rates of retirement may be higher than the entry of newly certified subspecialists into certain fields. These hypotheses emphasize the need to assess macrotrends as well as microtrends within each subspecialty and answers to these questions require datasets that longitudinally track individuals throughout their career.

This study is subject to several limitations. First, our analysis of the demographic characteristics was limited to data that were available in the ABP Certification Management System data for all first-year fellows over the entire study period. Historically, the ABP has collected responses to a question about the trainee's gender with a binary response option of male or female. This binary construct is not reflective of the full spectrum of gender identities. Our results represent an overly simplified understanding of the gender composition of the population of individuals entering pediatric medical subspecialty fellowship training that is dependent on the information available in the dataset. In the future, more complete information about the full spectrum of gender identities in the pediatric workforce should be collected. The ABP only recently began collecting race/ethnicity data and therefore we were unable to assess other demographic changes over time. Second, we do not have access to information about the reasons why individual pediatricians choose to pursue careers in some subspecialties more than others. Expected income and educational debt, work-life balance, and exposure to subspecialties in medical school or residency training are all potential factors. Third, although the $\mathrm{ABP}$ collects survey data on percent professional time in clinical care, teaching, administration, and research, that information was not linked to the data included in this analysis because timepoints and response rates vary. Fourth, we were unable to incorporate information about the number of clinicians exiting their fellowship program or retiring from their pediatric subspecialty careers after training because the ABP's data currently only permits aggregate trend analyses and not longitudinal analyses of individual trajectories. In this same vein, we do not have information on the number of IMGs who entered fellowship without any intention to practice in the US. Fifth, ABP data does not contain information about some pediatric subspecialists, such as Child Neurologists, who care for children but are certified through another medical board. In addition, our analyses do not account for individuals who obtain certification in multiple pediatric subspecialties, but the absolute number of these individuals is small and typically include subspecialists seeking certifications in joint boarded areas (Hospice and Palliative Medicine, Sleep Medicine, Sports Medicine, Medical Toxicology, and Transplant Hepatology). Finally, we do not have program- specific information on the change in size or the addition of new programs and the closure of programs over time.

\section{CONCLUSION}

Concerns about the adequacy of the pediatric subspecialty workforce are not explained simply by the number of individuals entering fellowship training. However, differences in the number of first-year fellows entering specific fields, shifts in the demographic characteristics of those entering fellowship training, and uneven regional distribution of fellowship programs may diminish the effective pediatric subspecialty workforce within fields and regions. Ideally, data on entry into subspecialty careers, percent of professional time devoted to clinical care, and attrition from the workforce would be combined in a longitudinal database to understand the supply of subspecialty pediatricians. These details are essential to better understand the nuances of the workforce available to care for the subspecialty needs of children and to develop programs and policies to address areas with shortages.

\section{ACKNOWLEDGEMENTS}

We thank the selected members of the American Board of Pediatric's (ABP's) Research Advisory Committee for their editorial review. This study was funded by the ABP Foundation, a nonprofit, supporting organization to the ABP. M.L.M. and G.L.F. were contracted to lead in developing the study design; analyzing the data; and drafting, editing, and submitting the manuscript. L.K.L. and A.T. are employees of the ABP and received salary compensation for their role in this research, including the collection, analysis, and interpretation of data; preparation of the manuscript; and the decision to submit the article for publication. The content is solely the responsibility of the authors and does not necessarily represent the official views of the ABP or the ABP Foundation

\section{AUTHOR CONTRIBUTIONS}

M.L.M. conceptualized and designed the study, carried out analyses, drafted the initial manuscript, and reviewed and revised the manuscript. G.L.F. and L.K.L. conceptualized and designed the study, and reviewed and revised the manuscript. A. T. carried out the analyses, and reviewed and revised the manuscript. All authors approve the final manuscript as submitted and agree to be accountable for all aspects of the work

\section{ADDITIONAL INFORMATION}

Competing interests: The authors declare no competing interests.

Publisher's note Springer Nature remains neutral with regard to jurisdictional claims in published maps and institutional affiliations.

\section{REFERENCES}

1. Goodman, D. C. The pediatrician workforce: current status and future prospects. Pediatrics 116, e156-e173 (2005).

2. Keller, D. M., Davis, M. M. \& Freed, G. L. Access to pediatric subspecialty care for children and youth: possible shortages and potential solutions. Pediatr. Res. 87, 1151-1152 (2020).

3. Weyand, A. C. \& Freed, G. L. Pediatric subspecialty workforce: undersupply or over-demand? Pediatr. Res. https://doi.org/10.1038/s41390-020-0766-0:https:// doi.org/10.1038/s41390-41020-40766-41390 (2020).

4. Freed, G. L., Moran, L. M., Van, K. D. \& Leslie, L. K. Current workforce of pediatric subspecialists in the United States. Pediatrics 139, e20163604 (2017).

5. American Board of Pediatrics. Physicians Workforce Data Book, 2018-2019 (American Board of Pediatrics, Chapel Hill, 2019).

6. Primack, W. A. et al. The US pediatric nephrology workforce: a report commissioned by the American Academy of Pediatrics. Am. J. Kidney Dis. 66, 33-39 (2015).

7. Collaco, J. M. \& Abman, S. H. Evolving challenges in pediatric pulmonary medicine: new opportunities to re-invigorate the field. Am. J. Respir. Crit. Care Med. 198, 724-729 (2018).

8. Bohnhoff, J. C., Taormina, J. M., Ferrante, L., Wolfson, D. \& Ray, K. N. Unscheduled referrals and unattended appointments after pediatric subspecialty referral. Pediatrics 144, e20190545 (2019). 
9. Ray, K. N., Bogen, D. L., Bertolet, M., Forrest, C. B. \& Mehrotra, A. Supply and utilization of pediatric subspecialists in the United States. Pediatrics 133, 1061-1069 (2014).

10. Okumura, M. J., Knauer, H. A., Calvin, K. E. \& Takayama, J. I. Caring for children with special health care needs: profiling pediatricians and their health care resources. Matern. Child Health J. 22, 1042-1050 (2018).

11. 2018 Children's Hospital Association. Pediatric workforce shortages persist. https://www.childrenshospitals.org/issues-and-advocacy/graduate-medicaleducation/fact-sheets/2018/pediatric-workforce-shortages-persist (2018).

12. Turner, A. L., Ricketts, T. \& Leslie, L. K. Comparison of number and geographic distribution of pediatric subspecialists and patient proximity to specialized care in the US between 2003 and 2019. JAMA Pediatr. e201124 (2020).

13. van der Velden, M. G., Barrett, M. K., Sampadian, G. A., Brilli, R. J. \& Burns, J. P. Pediatric critical care medicine training: 2004-2016. Pediatr. Crit. Care Med. 19, 17-22 (2018).

14. Abel, K. L. \& Nichols, M. H. Pediatric emergency medicine fellowship training in the new millennium. Pediatr. Emerg. Care 19, 20-24 (2003).

15. Cull, W. L., O'Connor, K. G. \& Olson, L. M. Part-time work among pediatricians expands. Pediatrics 125, 152-157 (2010).

16. Freed, G. L. et al. Variation in part-time work among pediatric subspecialties. J. Pediatr. 195, 263-268 (2018).

17. Starmer, A. J. et al. Gender discrepancies related to pediatrician work-life balance and household responsibilities. Pediatrics 144, e20182926 (2019).

18. Macy, M. L., Van, K. D., Leslie, L. K. \& Freed, G. L. Engagement in research among pediatric subspecialists at the time of enrollment in maintenance of certification, 2009-2016. Pediatr. Res. 87, 1128-1134 (2019).

19. Schell, G. J. et al. Strategic modeling of the pediatric nurse practitioner workforce. Pediatrics 135, 298-306 (2015).

20. Bridgemohan, C. et al. A workforce survey on developmental-behavioral pediatrics. Pediatrics 141, e20172164 (2018).

21. Smith, B. J. et al. Core curriculum to facilitate the expansion of a rheumatology practice to include nurse practitioners and physician assistants. Arthritis Care Res. 70, 672-678 (2018)

22. Basco, W. T. \& Rimsza, M. E. Pediatrician workforce policy statement. Pediatrics 132, 390-397 (2013)

23. Dayal, P. et al. Hospital utilization among rural children served by pediatric neurology telemedicine clinics. JAMA Netw. Open 2, e199364 (2019).

24. Guttmann-Bauman, I., Kono, J., Lin, A. L., Ramsey, K. L. \& Boston, B. A. Use of Telehealth videoconferencing in pediatric type 1 diabetes in Oregon. Telemed. $J$. E Health 24, 86-88 (2018).

25. Ray, K. N., Mehrotra, A., Yabes, J. G. \& Kahn, J. M. Telemedicine and outpatient subspecialty visits among pediatric Medicaid beneficiaries. Acad. Pediatr. 20, 642-651 (2020)

26. American Board of Pediatrics. Subspeciality fellowship tracking data. https:// www.abp.org/content/data-and-workforce (2020).

27. American Board of Pediatrics. Comparison of ABP data to the NRMP match data. https://www.abp.org/content/comparison-abp-data-nrmp-match-data (2020).

28. Umoren, R., Rybas, N. \& Frintner, M. P. The contribution of childhood and medical school location to the career paths of graduating pediatrics residents. Acad. Pediatr. 15, 557-564 (2015).

29. Freed, G. L. et al. Jobs and career plans of new pediatric subspecialists. Pediatrics 137, e20153298 (2016).

30. Weiss, $P$. et al. Funding sources and perceived financial insecurity in pediatric subspecialty fellowship programs. Acad. Pediatr. 19, 815-821 (2019).

31. Cohen, J. Statistical Power Analysis for the Behavioral Sciences (Lawrence Erlbaum Associates, 1988)

32. Rimsza, M. E., Ruch-Ross, H. S., Clemens, C. J., Moskowitz, W. B. \& Mulvey, H. J. Workforce trends and analysis of selected pediatric subspecialties in the United States. Acad. Pediatr. 18, 805-812 (2018).
33. Macy, M. L., Leslie, L. K., Boyer, D., Van, K. D. \& Freed, G. L. Timing and stability of fellowship choices during pediatric residency: a longitudinal survey. J. Pediatr. 198, 294-300 e291 (2018).

34. American Academy of Pediatrics. Graduating pediatric residents report factors influencing subspecialty choice. AAP News, 24 (American Academy of Pediatrics, 2020).

35. Mayer, M. L. \& Preisser, J. S. The changing composition of the pediatric medical subspecialty workforce. Pediatrics 116, 833-840 (2005).

36. Spector, N. D. et al. Women in pediatrics: progress, barriers, and opportunities for equity, diversity, and inclusion. Pediatrics 144, e20192149 (2019).

37. Shipman, S. A. \& Pan, R. J. D. Financing graduate medical education to meet the needs of children and the future pediatrician workforce. Pediatrics 137, 855-861 (2016).

38. Jimenez-Gomez, A., Moreira, D. C. \& Leon-Astudillo, C. International medical graduates in pediatrics: Should i stay or should i go? JAMA Pediatr. 173, 217-218 (2019).

39. Chakraborty, R., Rathore, M. H., Dreyer, B. P. \& Stein F. The pivotal role of the international medical graduate. Pediatrics 143 e20181189 (2019).

40. Al Ashry, H. S., Kaul, V. \& Richards, J. B. The implications of the current visa system for foreign medical graduates during and after graduate medical education training. J. Gen. Intern. Med. 34, 1337-1341 (2019).

41. Colenda, C. C., Applegate, W. B., Reifler, B. V. \& Blazer, D. G. 2nd COVID-19: financial stress test for Academic Medical Centers. Acad. Med. https://doi.org/ 10.1097/acm.0000000000003418 (2020).

42. Khullar, D., Bond, A. M. \& Schpero W. L. COVID-19 and the financial health of US hospitals. JAMA https://doi.org/10.1001/jama.2020.6269 (2020).

43. Silow-Carroll, S. \& Rodin, D. Forging community partnerships to improve health care: the experience of four Medicaid managed care organizations. Issue Brief (Commonw. Fund.) 19, 1-17 (2013).

44. Mayer, M. L. Are we there yet? Distance to care and relative supply among pediatric medical subspecialties. Pediatrics 118, 2313-2321 (2006).

45. Wong, C. A., Kan, K., Cidav, Z., Nathenson, R. \& Polsky, D. Pediatric and adult physician networks in affordable care act marketplace plans. Pediatrics 139 e20163117 (2017).

46. Maese, J. R., Seminara, D., Shah, Z. \& Szerszen A. What a difference a disaster makes: the Telehealth Revolution in the Age of COVID-19 Pandemic. Am. J. Med. Qual. https://doi.org/10.1177/10628606209335877 (2020).

47. Ray, K. N. \& Kahn, J. M. Connected subspecialty care: applying telehealth strategies to specific referral barriers. Acad. Pediatr. 20, 16-22 (2020).

48. Ehrich, J. et al. As few pediatricians as possible and as many pediatricians as necessary? J. Pediatr. 202, 338-339 e331 (2018).

49. Auerbach, S. R., Everitt, M. D., Butts, R. J., Rosenthal, D. N. \& Law, Y. M. The Pediatric Heart Failure Workforce: an international, multicenter survey. Pediatr. Cardiol. 39, 307-314 (2018).

50. Leavey, P. J. et al. The American Society of Pediatric Hematology/Oncology workforce assessment: part 2-implications for fellowship training. Pediatr. Blood Cancer 65 (2018).

51. Furth, S. L. et al. Relation between pediatric experience and treatment recommendations for children and adolescents with kidney failure. JAMA 285 1027-1033 (2001).

52. Nyenhuis, S. M., Akkoyun, E., Liu, L., Schatz, M. \& Casale, T. B. Real-world assessment of asthma control and severity in children, adolescents, and adults with asthma: relationships to care settings and comorbidities. J. Allergy Clin. Immunol. Pract. 8, 989-996 e981 (2020)

53. Ray, K. N., Kahn, J. M., Miller, E. \& Mehrotra, A. Use of adult-trained medical subspecialists by children seeking medical subspecialty care. J. Pediatr. 176, 173-181 e171 (2016).

54. Kokotailo, P. K., Baltag, V. \& Sawyer, S. M. Educating and training the future adolescent health workforce. J. Adolesc. Health 62, 511-524 (2018). 